RELACult - Revista Latino-Americana de Estudos em Cultura e Sociedade e-ISSN 2016/Atual: 2525-7870 | e-ISSN 2015/2016: 2447-018X

\title{
O samba junino e a diversidade de gênero numa manifestação fortemente masculinizada
}

\author{
El samba junino y la diversidad de género en una manifestación \\ fuertemente masculina
}

The samba junino and gender diversity in a strongly masculine

manifestation

\author{
Lic. Gustavo de Melo ${ }^{1}$
}

\begin{abstract}
Resumo
Este artigo é parte de uma pesquisa em andamento que tem como tema central a construção musical do samba junino, apresenta um pequeno esboço histórico e relata os resultados iniciais do trabalho de campo iniciado em 2015, observando, sobretudo, a participação de pessoas do sexo masculino no papel de rainhas do samba.
\end{abstract}

Palavras chaves: Cultura afro-brasileira, etnomusicologia, gênero, samba de roda.

\section{Resumen}

Este artículo es parte de una investigación en curso que se centra en la construcción musical de samba junino, se presenta una breve reseña histórica y los informes sobre los resultados iniciales del trabajo de campo se inició en 2015, teniendo en cuenta, en particular, la participación de los varones el papel de las reinas de samba.

Palabras clave: Cultura afro-brasileña, etnomusicología, de género, samba de roda.

\begin{abstract}
This article is part of an ongoing research that is focused on the musical construction of junino samba, presents a brief historical sketch and reports on the initial results of the field work started in 2015, noting, in particular, the participation of males the role of the samba queens.
\end{abstract}

Key words: African-Brazilian culture, ethnomusicology, gender, samba de roda.

\section{Introdução}

Com o tema, Samba junino: o samba duro e o São João de Salvador, venho realizando uma pesquisa de campo iniciada em fevereiro de 2016, numa comunidade de Salvador conhecida como Rua Chile da Capelinha, no bairro Engenho Velho de Brotas. Na verdade, meu interesse por essa manifestação cultural começa antes, quando, enquanto professor de música no Espaço Cultural Pierre Verger, Organização não governamental ligada

\footnotetext{
${ }^{1}$ Licenciado em Composição e Regência; mestrando em Etnomusicologia; Universidade Federal da Bahia UFBA; Salvador, Bahia, Brasil; gustavojotamelo@gmail.com.
} 
à Fundação Pierre Verger $^{2}$, tive a oportunidade de trabalhar com esse tema ministrando oficina de criação musical, em um período curto, mas que despertou em mim um grande desejo de conhecer um pouco mais sobre esse universo. Para esse trabalho, também organizamos palestras com pessoas que participaram ativamente desses eventos e/ou grupos de samba junino, para conhecer um pouco sobre o São João no bairro e o samba de roda de Salvador, sob a audiência de um público formado por professores, alunos e os moradores da redondeza. Em seguida, criamos um samba com o tema do projeto, como primeiro resultado da oficina, e de grande importância para a criação de um espetáculo, onde contamos toda uma gênese do samba junino, desde as novenas de Santo Antônio, reverenciada também pelos adeptos do candomblé, e que se estendia pelo São João e São Pedro, festas comemoradas especialmente no Nordeste em homenagem aos três santos católicos no mês de junho. Os alunos dessa oficina, todos moradores de bairros circunvizinhos, (Federação, Garcia e Engenho Velho de Brotas), além de criarem o tema do espetáculo cênico-musical, intitulado "O Samba dos Engenhos", em referência aos bairros, Engenho Velho de Brotas e Engenho Velho da Federação, ajudaram a construir o repertório, com as músicas de samba de roda que conheciam das festas de São João que aconteciam todos os anos nestes bairros. A partir dessa experiência, me dediquei a procurar entender como o samba junino, que foi tão importante para o surgimento de fenômenos como "Axé music e pagode na Bahia", passava por um momento tão difícil, de enfraquecimento, quase extinção de um movimento que teve seu auge na década de 80 do século passado. Os mais antigos relatos sobre o samba junino são da década de 50 do século XX, informações que foram vistas em Döring (2016, p. 122) e em conversas informais com pessoas ligadas à cultura negra em Salvador.

Esse primeiro contato com o samba junino me proporcionou a oportunidade de participar em um grupo, o samba Santamaro do Engenho Velho da Federação, que tem como líder o cantor e compositor Nem Cardoso do terreiro Bogun, no mesmo bairro. Nesse grupo pude aprender um pouco sobre samba de roda e conhecer muitas pessoas que se dedicam a esse gênero musical/cultura/música específica e sua vinculação com o São João. Permaneci por pelo menos dois anos tocando violão com o grupo. Esse período de participação como instrumentista foi extremamente importante para acessar o universo do samba junino de forma mais profunda, conhecendo os atores principais, possibilitando conhecer seus códigos e dessa forma, viabilizando a penetração nesse ambiente único, mas que está ligado a uma rede de interligações de caráter social, econômico, afetivo, musical, sexual, racial, estético, etc.

\footnotetext{
${ }^{2}$ Órgão criado pelo fotógrafo e antropólogo francês Pierre Verger para preservar e divulgar sua obra.
} 
(SEEGER, 1992, 88). Nesse artigo irei focar num conflito resultante da relação de gêneros no samba junino, em particular, nas rainhas do samba junino, posto antes associado, ou melhor, ocupado pelas mulheres e hoje, num contexto mais diversificado. Para isso, trago um pouco da análise etnográfica realizada no Samba Chile, juntamente com entrevistas e observações feitas em campo, junto ao grupo onde atuo como violonista desde janeiro de 2016.

\section{Um pouco do universo das rainhas "trans" no samba junino}

Que a atuação feminina nos diversos campos da sociedade foi negada e/ou "invisibilizada" na história isso é uma fato. No Brasil, em manifestações culturais como o samba, recentes trabalhos observam a enorme contribuição e/ou participação das mulheres, não apenas de forma passiva, fornecendo alimentação, preparando um ambiente adequado para surgimento, criação e transformação do samba carioca como símbolo maior da nossa cultura, mas também como compositoras, bem como instrumentistas. No texto A casa do samba, o samba da rua: relações de gênero, arte e tradição no samba carioca, do autor Rodrigo Cantos Savelli Gomes (2013, p.354-379), apresenta um texto que aborda a atuação feminina no samba carioca como protagonista, não na passividade descrita pelos historiadores, mas atuando musicalmente, fora dos limites intrínsecos da casa. Discute essa invisibilidade como consequência preponderante do machismo "institucionalizado" com todos seus recursos "midiáticos" nas bibliografias dos cânones do samba. Através de uma perspectiva crítica/historiográfica busca corrigir inúmeras falhas na abordagem descrita pela história do samba, numa revisão ampla. Como questão principal nas discursões sobre gênero, o texto traz inúmeras informações que apontam para uma presença feminina muito mais participativa, revelando uma atividade mais engajada nos processo de criação, apesar das dificuldades imposta pelo sistema, que lhes atribui diversas atividades e até imposições matrimoniais, por exemplo. (GOMES, 2013, p. 365).

O samba junino, que se apresenta com uma configuração excessivamente masculinizada, tem revelado em minhas pesquisas de campo, numa manifestação cuja figura feminina é vista no topo de alguns desses grupos, ocupando lugares privilegiados, seja na coordenação e/ou direção desses grupos, bem como na sua formação. Outra característica, importante para se entender a relação com a comunidade, é a vinculação desses grupos de samba junino com a família e consequentemente a todos os recursos que giram em torno da "matrilinearidade que permeia a cultura afro-brasileira." (GOMES, 2013, p. 376) Também observei a presença de mulheres na criação musical e também na execução instrumental. 
Sob uma ótica histórica, reduzindo o âmbito para um contexto menor, como é o caso do samba de roda do recôncavo na Bahia, tombado pelo patrimônio imaterial da humanidade em 2005 pela UNESCO, é percebida a participação das mulheres, não apenas como elemento coreográfico, exibido com enorme maestria pelas sambadeiras nas rodas de samba, mas também, protagonizando e até conduzindo muitos grupos de samba, mesmo que ainda em menor número que os homens, prevalecendo a figura masculina, apontado como principal ator dentro do universo criativo dessa manifestação cultural.

Dentro de uma área mais urbana, em Salvador precisamente, uma vertente do Samba de roda surge nos festejos juninos como alternativa primeira para os moradores de bairros periféricos, homens e mulheres que não viajavam para a festa de São João no interior. Eram formados por jovens negros que, de forma espontânea, saiam às ruas tocando instrumentos de percussão como, atabaques, tamborins e marcação, etc., cantando cantigas de Samba de Roda, músicas de forró e sucessos das rádios, "arrastando" grande quantidade de pessoas, tudo isso ao ritmo do samba. Eram os sambões. Nesse contexto então, criou-se o samba junino, onde as comunidades organizavam grupos com roupas caracteristicamente padronizadas, com músicas compostas com o tema junino, retratando o universo da festa com o samba ${ }^{3}$. Visto este contexto inicial, superficialmente apresentado, pergunta-se: De que forma acontece a participação dessas pessoas no Samba Junino levando-se em conta a diversidade de gênero? Esse pequeno esboço etnográfico constitui-se em parte de uma pesquisa em etnomusicologia, ainda em andamento, que venho realizando através do CAPES e da PPGMUS-UFBA no bairro Engenho Velhos de Brotas, Salvador, Bahia, que busca entender os processos composicionais do Samba Junino, visto que, dessa manifestação, surgiram inúmeros músicos da cultura afro-baiana, constituindo-se também num elemento socializador entre os membros de regiões periféricas da cidade, processo esse, muito mais que artístico/criativo, apresentando então, questões sociais relevantes para seu entendimento. (MERRIAN, 1964, p. 123).

Como relatado no início do texto, meu primeiro contato com o samba junino, no que se refere a minha atuação na função de músico, veio através de um convite feito por um aluno meu de violão. Através dele, comecei a participar de um grupo ligado ao samba junino, o samba Santamaro do Engenho Velho da Federação, bairro predominantemente negro de Salvador e que abriga muitos sambas juninos. Lá percebi a grande participação das pessoas nos ensaios que acontecem nas ruas, principalmente de mulheres da comunidade, mas

\footnotetext{
${ }^{3}$ Essas informações à respeito do samba junino foram colhidas em entrevistas que venho realizando desde 2015 , e em vídeo publicado em 2012 no youtube de um especial produzido pela TVE.
} 

e-ISSN 2016/Atual: 2525-7870 | e-ISSN 2015/2016: 2447-018X

também, um público formado de homens, crianças, famílias que iam se divertir, beber, comer e também vender, gerando uma cadeia produtiva, favorecendo a economia local. Em 2015, tive meu projeto aprovado com o tema "O Samba Junino: o samba duro e o São João de Salvador", como mencionado anteriormente. Na mesma época, fui convidado para integrar o Samba Chile da Capelinha, nome dado em homenagem a uma Rua do Engenho Velho de Brotas como o mesmo nome. Esse grupo foi criado em 1987 pela mãe de um dos integrantes, amigo meu dos tempos do Samba Santamaro, minha primeira experiência como sambista nessa modalidade de samba. Desde então, venho observando a participação das pessoas como criadoras de músicas de Samba junino, articuladores culturais e o público em geral. Dessas observações, notei a participação das mulheres, não apenas como dançarinas sensuais, dado que ainda prevalece nessas relações, mas também em diversas outras posições, seja como diretoras e/ou assistentes de grupos, articuladoras em organizações culturais como no grupo de samba junino "Unidos do Capim”, etc. Percebi também a forte presença de transgêneros do sexo masculino como dançarinos, muitas vezes, substituindo o papel que seria das "rainhas do samba”. Nas falas dos mais antigos sambistas e articuladores/promotores culturais do samba junino, bem como em algumas músicas, pude notar um profundo caráter de exclusão e/ou discriminação desses atores. Isso, que envolve a presença do cotidiano em suas letras, proporciona uma lógica perversa, sendo essa, um tipo de "sátira machista" entre seus participantes, e que tem como "carrasco principal” os cantores. (LIMA, 2016, p.34). Na minha lógica, um fator preponderante nas relações de gênero nos ensaios do samba junino é a dualidade entre o sensual/sexual, visto nas apresentações das mulheres dançando, e o exótico, quando homens e ou transgêneros. Nos ensaios do samba Chile, por exemplo, foi escolhido como rainha do samba, um rapaz, reconhecido não apenas pela sua grande habilidade como dançarino, mas também pelo seu engajamento no grupo, participando de todas as reuniões e colaborando de forma muito ativa para a realização dos ensaios do samba na Rua Chile, seja na arrumação dos instrumentos, ou na ornamentação do palco, etc. Importante relatar que, esse fato, o de ter um homem como rainha, gerou grande polêmica, principalmente entre os articuladores e membros mais antigos, fato observado nas muitas conversas que eu pude ter com alguns desses participantes. Também pude ver essa situação em um evento promovido pela Liga do Samba Junino ${ }^{4}$, quando na gravação de um vídeo feito para um documentário,

\footnotetext{
${ }^{4}$ A Liga do Samba Junino é uma entidade formada por diversos grupos de samba junino de Salvador e que tem como dirigentes o músico Nonato do samba Mucungê e Reinaldo Nascimento, ex-vocalista do grupo Terra samba.
} 
dentro das atividades feitas para fortalecer o pedido de tombamento do samba junino, promovido pela prefeitura de Salvador neste mesmo período. Isso ocorreu de forma tumultuosa quando foi exigida a retirada "de nossa rainha" do palco, para a entrada de uma mulher, fantasiada com roupa bem sensual para acompanhar a banda na gravação do vídeo. Esse ocorrido gerou certa insatisfação de parte do grupo e levou um enorme constrangimento ao rapaz que estava no papel da rainha do samba Chile, sendo ele morador do bairro e residente na Rua Chile da capelinha, participativo e amigo de todos.

Outro momento importante dessa pesquisa, para poder observar essa participação, foi em entrevista com Poquinha, uma das mais antigas dançarinas, transgênero e participante do samba do Morro no bairro da Federação, numa comunidade de mesmo nome. Ela me contou sobre sua participação nos muitos sambas e de como já foi discriminada, falando com certa mágoa, mas também com orgulho por ter passado por todas essas experiências, para se transformar num símbolo do samba junino, sendo reconhecido pelos integrantes do grupo, fato que gerou inclusive a criação de uma música em sua homenagem.

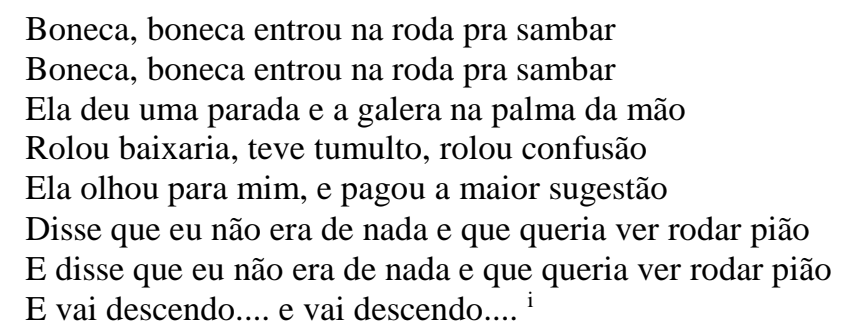

Essa música foi feita a pedido do presidente que sugeriu a um dos seus integrantes compositores que fizesse uma música com o tema boneca, visto que ela, Poquinha, não gostava de ser chamada de "viado".

Outra questão relacionada à presença de homens na função de rainhas, principalmente hoje em dia, é a discursão que gira em torno do fato de que as mulheres não querem mais sambar. Isso sugere que, talvez, as mulheres estejam vivendo outra realidade, ainda difícil, porém, com uma busca maior por empoderamento, engajado no fortalecimento do feminismo, levando a um maior esclarecimento sobre sua posição na sociedade. Para Lazinho, presidente do samba do Morro:

\footnotetext{
...hoje em dia, você chega na roda... no samba, só os viado é que quer chegar e... fechar. Aí eu fiz a música:

E tem viado aí? Tem sim! Traz ele pra cá

Traga o viado pra roda e bota esse viado pra sambar

As mulheres hoje em dia na roda não querem entrar

Os viado quando chega, já chega querendo fechar

Ele samba com alegria, satisfação, muito prazer

Ele mostra que sabe sambar, ele mostra que sabe mexer
} 
Então entra na roda viado e mostra pra elas o que elas quer ver

Não sei se, apenas a necessidade em ter uma atração a mais para a realização e fortalecimento da festa seja fator preponderante para o reconhecimento de "Poquinha" como importante ou até indispensável para o samba, o que me parece bem provável. Por outro lado, nota-se também a tentativa de impor determinada superioridade com o uso do termo "viado" descrito na letra da música.

Perguntada sobre o que ela achava da música feita em sua homenagem, Poquinha respondeu da seguinte forma:

Maravilhosa! Eu acharia que essa música deveria ter o meu nome. (...)

Poquinha. "Chega pra cá Poquinha (pra sambar?)", que seria bem melhor viu Lazinho?! Meu nome. Melhor que "tirar... botar essa bicha, esse viado pra sambar". Bota Poquinha pra sambar, que é bem melhor.

Nota-se um discurso político, a exigência de um maior respeito, um engajamento maior, provavelmente favorecido pelo crescimento e empoderamento da mulher em nossa sociedade.

Poquinha também foi um dos que encabeçaram o desfile da Liga do samba junino no evento de tombamento do samba junino, ocorrido no parque solar boa vista no dia 19 de junho de 2016, evento que contou com a participação da vice-prefeita Célia Sacramento, os cantores, Ninha ex-timbalada e Reinaldo Nascimento ex-Terra samba, e mais diversos outros grupos de samba junino, dentre outras celebridades locais como o apresentador e ator Jacqson Costa, o presidente da Fundação Gregório de Mattos e diretor teatral Fernando Guerreiro, juntamente com o Conselho Municipal de Política Cultural.

Além de Poquinha, outros dançarinos foram observados, tanto mulheres quanto homens. E apesar do grande número de "homens trans", sempre presentes nos ensaios, algumas mulheres se destacam principalmente pela sensualidade. Nos comentários de alguns músicos, fica claro o desejo de que tivessem mais mulheres dançando nos sambas, desejo esse, incentivado pelo apelo sexual das suas danças, dado que pode também ser a chave para a relação, um tanto quanto hostil, para com os "homens trans".

O trabalho etnográfico realizado durante esse período junto à comunidade da Rua Chile da Capelinha tem me proporcionado a descoberta dos inúmeros personagens que produzem essa história, num contexto bem diverso. Uma rua que preserva uma imagem de Santo Antônio ao lado dos ensaios do samba junino não poderia ser tão significativa. Entre os tantos pedestres, moradores que transitam por entre os músicos nos dias de ensaio, com suas bíblias debaixo do braço, ou o pacote dos pães, estava eu, tentando observar amplamente o 
quadro que me era apresentado para entender de forma consciente o sentido por trás de cada figura. (SEEGER, 1992)

\section{Conclusão}

O contexto relatado é parte de um contexto maior, que se subdivide em diversos outros, para formar a teia da vida, que é a base do fazer musical e sem a qual não existiria. Ainda falta um longo caminho a percorrer, e nele, outros personagens serão apresentados, possibilitado uma melhor compreensão da criação musical revelada pelo samba junino, objetivo maior desse projeto de pesquisa. Como visto no texto, esses atores funcionam como uma peça necessária para a própria existência da cultura do samba junino, como num quebracabeças, montado a partir dessas células, para a construção do objeto central, que é o próprio samba junino, mas que também faz parte de outro contexto ainda maior, onde, o personagem "trans", serve de inspiração para o compositor viabilizando a criação, e o produto de sua criação realimenta o Samba junino.

\section{Referências}

DÖRING, K. Cantador de Chula: O samba antigo do Recôncavo. 1. ed. Salvador, BA: Pinaúna, 2016. 256 p.

GOMES, R. C. S. A Casa do Samba, o Samba da Rua: relações de gênero, arte e tradição no samba carioca. In: NOGUEIRA, I. P.; FONSECA, S. C. (Org.). Estudo de Gênero, corpo e música: abordagens metodológicas. Goiânia, Porto Alegre: ANPPOM, 2013, p. 354 - 379. Série pesquisa em música no Brasil, v. 3.

LIMA, A. Uma crítica cultural sobre o pagode baiano: música que se ouve, se dança e se observa. 1. ed. Salvador, BA: Pinaúna, 2016. 128 p.

MERRIAN, A. P. THE ANTHROPOLOGY OF MUSIC. 1. ed. Evanston, Illinois: Northwestern University Press, 1980. 358 p.

SANDRONI, C. (Coord.). Samba de Roda do Recôncavo Baiano. Brasília: IPHAN, 2016.

SEEGER, A. Ethnography of Music. In: Ethnomusicology: an introdution. 1. ed. New York, London: W.W. Norton \& Company, 1992. cap. IV, p. 88 - 109.

\footnotetext{
${ }^{\text {i }}$ Entrevista realizada em 13 de junho de 2016 com Poquinha e Lazinho no bairro do Garcia no ensaio da Liga do Samba Junino.
} 